\title{
La secularización desplazada. La vanguardia en el proceso de la antimodernidad
}

\section{Displaced secularization. The vanguard in the anti-modernity process}

\author{
Ana Davis \\ Universidad de Sevilla, España \\ adavis@us.es
}

Resumen: El presente estudio propone una definición de "vanguardia" a partir de su intento de secularizar el arte del ideal y sublimidad románticos. Para ello, se parte de una noción amplia de "secularización" vinculada al proceso de la modernidad, un proceso de desacralización que la vanguardia intentó aplicar al arte. Nuestra sugerencia es que ese intento fue fallido y que la vanguardia derivó en una resistencia a lo moderno, en clara contradicción a su discurso de ruptura y novedad. El trabajo se divide en tres partes: la primera se centra en delimitar las nociones de "secularización", "modernidad" y "antimodernidad"; la segunda, en definir la vanguardia en relación con su intento de secularizar el arte; finalmente, la tercera expone el fracaso de dicho intento y lo ejemplifica en el terreno literario mediante la antítesis entre poesía y novela.

Palabras clave: vanguardia, modernidad, secularización, poesía, novela.

Abstract: The following paper proposes a definition of "avant-garde" based on its attempt to secularize the art from the romantic ideal and sublimity. To do this, it starts from a broad notion of "secularization" linked 
to the process of modernity, a process of desecration that avant-garde tried to apply to art. We suggest that this attempt was unsuccessful and that avant-garde resulted in a resistance to the modern, in clear contradiction to its discourse of rupture and novelty. The study is divided into three parts: the first one focuses on delimiting the notions of "secularization", "modernity" and "anti-modernity"; the second on, in defining the avant-garde in relation to its attempt to secularize art; finally, the third one exposes the failure of this attempt and exemplifies it in the literary field through the antithesis between poetry and novel genre.

Keywords: Avant-garde, Modernity, Secularization, Poetry, Novel genre.

Recibido: 20 de octubre de 2020

Aceptado: 5 de mayo de $202 \mathrm{I}$ https://dx.doi.org/I O.I 5 I 74/rv.vi 4i29.575

\section{La secularización entre dos modernidades}

La secularización, en un sentido amplio, puede definirse como el proceso de emancipación o adquisición de autonomía respecto de un paradigma anterior sujeto a leyes dogmáticas, inmutables y atemporales. Para que tal fenómeno se inicie, es preciso un proceso previo de autoconocimiento y autorreflexión con el fin de distinguirse respecto de aquello de lo que se quiere emancipar. De ahí que el inicio de la secularización moderna fue posible gracias al despertar de la consciencia que supuso la modernidad, al ser esta un umbral de entrada hacia la categorización histórica del pensamiento y su consecuente reflexión de lo moderno frente a lo anterior. A partir de la modernidad, no es el pasado lo que se ha de categorizar sino el propio presente: "la modernidad [...] tiene que extraer su normatividad de sí misma” (Habermas, 1993: 17). A causa de dicha autodefinición, la sociedad empieza a escindirse y lo 
que antes estaba armónicamente unido (historia, ciencia, religión, cultura, arte, etc.) progresivamente se va diferenciando entre sí.

En el primer capítulo de La historia de la literatura como provocación, Hans-Robert Jauss traza una evolución del concepto de modernidad, situando su inicio en el Renacimiento, es decir, cuando lo moderno significa la oposición a un pasado inmediatamente anterior, aunque recuperando la Antigüedad (2000: 38-39). En el siglo XVIII, dice Jauss, se revierte ese significado al concebir la historia a partir de la razón crítica y "avanzando sin cesar en la época del progreso" (2000: 44). Se busca así asimilar la "perfectibilidad" en el campo de las artes como en las ciencias exactas; en otras palaras, "moderno" equivale a "clásico": "La nueva modernidad [...] designa su oposición respecto a la Antigüedad con una palabra que, con este significado, debe tomar prestada de los hermanos Schlegel: el adjetivo klassich, 'clásico'” (51). Tal equivalencia se verá desbancada cuando el romanticismo, pese a mantener la noción de historia como progreso, llegue paradójicamente a las conclusiones opuestas; a partir del siglo XIX, "modernidad" se opone a lo clásico y a lo antiguo porque revaloriza lo efímero, lo transitorio y reivindica el "derecho propio a lo nuevo" de cada época y generación (26). ${ }^{1}$ Porque, concluye Jauss, en el siglo xix la modernidad comienza a considerarse la frontera entre un mundo anterior lejano en el tiempo y el presente percibido como familiar (53).

Esa historización del arte iniciada en el romanticismo culmina en los movimientos de vanguardia y tiene como consecuencia la pérdida de los modelos de la tradición canónica, dando protagonismo absoluto a la estética de la novedad (Del Gizzo, 2015: 61).

${ }^{1}$ Jauss ejemplifica dicho cambio mediante la figura de Stendhal, a quien atormentaba la idea de que lo moderno, al ser temporal, siempre se torna clásico; por tanto, "romanticismo" y "clásico" no pueden oponerse. De ahí que fuera Stendhal el primer escritor en tematizar la experiencia de lo histórico en sus novelas. 
Debido a esa pulsión hacia la novedad, se rechaza la asimilación iluminista entre lo moderno y lo clásico. Así, podríamos afirmar que el siglo xix rompe de lleno con una noción de "modernidad" como sinónimo de progreso, aunque no se haya dejado de emplear por pensadores posteriores, sobre todo, adscritos al marxismo. ${ }^{2}$ Esa es una de las contradicciones señaladas por Jürgen Habermas en El discurso filosófico de la modernidad cuando explica que fue la misma modernidad la que se opuso a sus propios postulados racionales: "Se está rechazando, precisamente, lo que la modernidad, al tratar de cerciorarse de sí misma, pretendió con los conceptos de autoconciencia, autodeterminación y autorrealización” (1993: 399). Por ello, Jorge Álvarez Yágüez (2021) propone dos modos de entender la modernidad para explicar la historia de las ideas desde el siglo xvi hasta la actualidad. Según un primer modo de entenderla, la modernidad se iniciaría a partir de la Conquista de América e incluiría el primer intento de secularización en la polémica Reforma/Contrarreforma como parte de su estructura de pensamiento. Un segundo modo sería a partir de la revolución filosófica del siglo Xviı cuando el pensamiento tiende a ser racional, materialista, empírico y científico para erigirse como modelo de conocimiento. Ambas nociones -sigue Álvarez Yágüez-corren paralelas a lo largo de la historia, confundiéndose, superponiéndose, pero perviviendo diferenciadas en el tiempo -aunque, como explica Eagleton (1997), la primera se impone como la hegemónica a partir del siglo XIX-.

La primera acepción explicaría la emergencia de un romanticismo antiliberal contra el progreso y el utilitarismo que Juan José Sebreli (2000) denomina "romanticismo antimoderno" y Antoine Compagnon (2005), el "modernismo antimoderno". La segunda,

${ }^{2}$ Por ejemplo, la noción de "modernidad" empleada por Terry Eagleton en Las ilusiones del posmodernismo (1996). 
en cambio, originaría el arte clásico, racional y realista. Partiendo de esa dicotomía, Sebreli propone una historia de las ideas culturales y artísticas de la modernidad a partir del pensamiento dialéctico -dos modernidades-. Sebreli hace uso del significado de "modernidad" como el cambio que se inicia en el siglo XVI cuando la conciencia histórica empieza a reemplazar al pensamiento medieval en un lento proceso que se acelera en el siglo xvirI a partir del Iluminismo, la Ilustración, el cientificismo y la centralidad de la razón. Todas estas "transformaciones de lo moderno" -empleando la terminología de Jauss (1995) - que buscan dejar atrás los dogmas irracionales anteriores, se verán enfrentadas a una resistencia por la nostalgia del pasado premoderno, cuando el tiempo no se sufría con agonía ni existían las consecuencias negativas del progreso: la pérdida de lo espiritual a favor de lo material, desigualdad social tras la falacia de la democracia, industrialización y mercantilización de la vida, distanciamiento entre el burgués y el proletario, etc. Sebreli ve, en este sentido, una línea de continuidad histórica desde el drama Barroco -primer eslabón artístico que manifiesta ese desasosiego moderno- hasta la vanguardia, pasando por el romanticismo. La búsqueda de la novedad, la glorificación de lo irracional, el gusto por la locura, el sueño, la estética de lo feo, son elementos comunes que comparten, aunque con matices diferenciadores propios de su tiempo. Consiste en una resistencia artística a la modernidad que Sebreli denomina "romanticismo antimoderno", un arte que se presenta a sí mismo como "moderno" pero que se enfrenta a la modernidad entendida como el pensamiento que genera el racionalismo de la Ilustración. En contraste a ese arte romántico antimoderno, habría una corriente opuesta, más silenciosa y con menor resonancia, que surge a partir del racionalismo y el cientificismo del siglo xviII, y que el crítico sintetiza bajo el término de "clásico", cuya manifestación artística más representativa sería el realismo decimonónico (Sebreli, 2000: 419). 
La propuesta de Compagnon se acerca a la de Sebreli al diferenciar entre una modernidad -romántica- que se resiste a otra modernidad -equivalente a "progreso"-; y una "corriente subterránea de la modernidad" (2007: 22) que rechaza el racionalismo, el cartesianismo la Ilustración, el optimismo histórico, y que tiene a Baudelaire como su figura más representativa. ${ }^{3}$ En Las cinco paradojas de la modernidad (1990), Compagnon definía la modernidad como el culto a lo nuevo, un imperativo de renovación contradictorio, cuya sexta paradoja vislumbró en su obra posterior, Los antimodernos (2005), y que entiende como la incesante superación de sí mismo. El crítico pone como ejemplo la observación de Sartre hace respecto a que Baudelaire avanza sin dejar de mirar un espejo retrovisor, es decir, consciente de aquello que deja atrás, pero sabiendo que es irrecuperable y avanzando a su pesar; por ello, es un "moderno antimoderno", a diferencia de los vanguardistas, a quienes Compagnon considera los "modernos enceguecidos de futuro". El autor delinea la "modernidad antimoderna" a partir de seis características: la tendencia a la contra-revolución política y estética; la hostilidad al pensamiento ilustrado; la actitud pesimista o resignada -que se traduce en el refugio artístico-; el "pecado original" -o la estética de lo grotesco-; lo sublime, y el estilo de vituperación o imprecación antiburgués (Compagnon, 2007: 139). Pero Compagnon no incluye la vanguardia dentro de esa modernidad antimoderna, algo que dista de la teoría de Sebreli, quien sí concibe la vanguardia como antimoderna, opinión que suscribimos y que intentaremos justificar mediante el proceso de secularización ilusoria de la vanguardia.

Partiremos, pues, de las tesis de Sebreli y Compagnon porque compartimos la visión de Sebreli de la vanguardia como última

${ }^{3}$ El crítico se basa en la definición de "progreso" como "fanal oscuro" de Baudelaire: "esa linterna moderna [que] ensombrece todos los objetos del conocimiento” (Compagnon, 2007: 86). 
manifestación de ese romanticismo antimoderno en el arte. Nuestro propósito es, en suma, explicar el intento de secularización de la vanguardia con respecto al ideal clásico, a partir ambivalencia de la modernidad en su "derecho hacia lo nuevo". En esa transformación hacia lo moderno, existe una nostalgia romántica del pasado, una tendencia moderna que impidió que la pretendida secularización artística de la vanguardia no fuera abolida sino fue desplazada por una sacralización distinta a la romántica. Dicho de otra manera: la modernidad hegemónica que dominó el pensamiento artístico a partir del siglo XVI fue tan mistificadora como el paradigma al cual se había enfrentado, dando como resultado una secularización desplazada o una alienación disfrazada de autonomía que, en el arte, culminó en las vanguardias.

\section{La vanguardia o el suicidio de Narciso ${ }^{4}$}

Todo movimiento de vanguardia es una instancia de inflexión en las luchas internas de su campo cultural que, en su afán de renovación, impulsa un cuestionamiento del canon, la tradición, y la propia noción de arte. Según Del Gizzo, es un período transitorio, un "punto de inflexión en el devenir artístico que condensa el límite entre lo que ya no es y lo que todavía no es, señalando de ese modo las cesuras históricas" (2017: 17). Para su definición, la autora se basa en la expresión de "época de umbral" de Jauss, esto es, un período en que configuraciones discursivas, formaciones ideológicas y expresiones artísticas se encuentran en un estado de transformación. En el terreno artístico, la vanguardia sería la manifestación explícita de dicha transición al llevar a cabo la revisión, aceptación, rechazo, y selección de obras y autores anteriores, y al posicionarse

${ }^{4}$ Algunos postulados expuestos en el presente apartado fueron elaborados previamente, de manera más sintetizada en el volumen de nuestra autoría Vanguardia y refundación nacional en Adán Buenosayres (Davis González, 2021). 
frente a los paradigmas estéticos en boga. La vanguardia es, en este sentido, la culminación de la conciencia histórica que caracteriza la modernidad y que llega a su máximo apogeo en el siglo xx, debido a la secularización de la vida, la democracia, los nacionalismos y las guerras que caracterizaron la centuria.

Si bien no todo el arte del siglo xx fue vanguardista, indica Del Gizzo que sí compartió con la historia la vocación por reiniciar desde cero distintos aspectos de la sociedad: política, cultura, costumbres cotidianas, etc. La vanguardia es el resultado de un proceso que comienza en el programático siglo XIX, cuando se originan las novedades esenciales que condicionan la historia en todos sus matices: la revolución industrial en la ciencia, las independencias americanas y unificaciones de las naciones europeas, la filosofía de Nietzsche y la relectura del marxismo y, en el arte, la culminación de la estética romántica europea que había despuntado a finales del xviII. Si el siglo XIX se caracteriza por la promesa en diversos ámbitos, el xx intenta poner en práctica lo que antes eran meras ilusiones. ${ }^{5}$ La vanguardia es, como queremos demostrar a continuación, el momento en que el artista se enfrenta a contradicciones que no sabe resolver, pero cree que sí resuelve mediante una emancipación del ideal romántico anterior. Si los románticos buscaban trascender la naturaleza y acceder al ideal, la vanguardia, en su hipotética secularización, dará un paso más al desacralizar ese ideal e intentar acceder a lo real. Porque emanciparse del ideal es asumir la categorización histórica del arte como algo que puede acabar, que es susceptible de un final. Y fue ese fin del arte el que la vanguardia se negó a reconocer, volviéndose esclava de sus propios principios dogmáticos.

${ }^{5}$ Para profundizar en el germen decimonónico de la vanguardia, consultar a Mario De Micheli (2015), Renato Poggioli (2011) y Alain Badiou (2005). 
Mario De Micheli establece un corte en el pensamiento romántico a partir de 1848 porque las oleadas revolucionarias condicionan la función del artista europeo en la sociedad. El año de1848 significa un umbral entre la elevación sagrada del arte y su descenso a la vida. Aunque la vanguardia sea la culminación de ese descenso, ya en el siglo xix se señala esa necesidad. Visto de esta manera, el romanticismo adelanta muchos rasgos de la vanguardia al tomar consciencia de la historicidad de la producción artística, una clarividencia de la cual se sirve la vanguardia para devolverle al arte su flujo vital (Del Gizzo, 2017: 5). El romanticismo es así "vanguardia en potencia" (Poggioli, 2011: 52); o, en palabras de Edoardo Sanguineti, "vanguardia" es la culminación de la "crisis romántica de lo sublime": "esa especie de nostalgia de lo sublime y esa imposibilidad reconocida de alcanzarlo que expresan [...] la mala conciencia del arte romántico burgués" (1972b: 90) con la diferencia, añadimos, de que la nostalgia de lo sublime ya no se coloca en el pasado sino que se ubica en el futuro, en una suerte de nostalgia inversa de la vanguardia.

"Vanguardia" implica un cuestionamiento continuo sobre la realidad presente; no porque el arte de vanguardia sea un reflejo de la realidad, sino porque la vanguardia busca indagar en la relación entre arte y realidad. Es un cuestionamiento "continuo" porque la vanguardia abarca todos los movimientos artísticos que durante el siglo xx se adjudicaron la tarea de renovar el arte y la tradición mediante la ruptura; ${ }^{6} y$ "presente", porque el fin que comparten todas las corrientes de vanguardia es captar el instante fugaz al operar en un momento de transición, de cesura. Su experimenta-

${ }^{6}$ Del Gizzo: "El arte del siglo xx fue vanguardista porque compartió con su época el impulso de destrucción para comenzar todo de nuevo. [...] La vanguardia fue la forma en que el arte obedeció a esa lógica revolucionaria de ruptura y refundación; en otras palabras, constituyó la estetización de esa exigencia” (2017: 9-12). 
ción se centraba en el presente porque clausuraron las formas del pasado e intuían una estética futura aún en potencia, inexistentes. Ello genera, por un lado, una "estética agónica" (Poggioli, 2011), que proyecta lo fugaz, la destrucción, la angustia del instante presente; por otro, la "estética de umbral" (Del Gizzo, 2017), una experimentación que proyecta artísticamente la conciencia de lo transitorio. El debate con lo real será una constante discusión entre sí y cada movimiento de vanguardia se legitimará como profeta de su verdad o realidad.

Como explica Badiou, el siglo xx se caracterizó por la "pasión por el presente" como resultado del contexto histórico-político, un espíritu de época hastiado ya de la indeterminación y las promesas, dispuesto a concretarlas: las constantes guerras que azoran Europa provocan un giro en la orientación de las obras artísticas. La muerte, dice Badiou, enfrenta al artista al puro presente, un tempus fugit más trágico que el barroco, pues el individuo se sabe muerte y "muerte", tras la progresiva secularización de la vida, significa vacío. ${ }^{7}$ Berman (2011) considera que la idea de estar viviendo la plenitud de los tiempos es algo inherente a la modernidad, y Poggioli alude al "sentimiento agónico" del vanguardista (2011: 75). Por su parte, Badiou explica que el vanguardista lidia con esa sensación de muerte inminente, no mediante la destrucción sino a través de la sustracción, una suerte de "nihilismo activo" (2005: 79). De ahí la metáfora del término "vanguardia" no solo como parte del ejército que va por delante sino también como ese grupo de individuos que toman consciencia de la inminencia de la muerte. Así, si el

${ }^{7}$ Hauser: "La experiencia actual del tiempo consiste sobre todo en la conciencia del momento en que nos encontramos; en una conciencia del presente" (1992: 285). Poggioli, por su parte, denomina "presentismo" a este estado en que se encuentra el vanguardista. En la literatura hispanoamericana, el poema Altazor (1931) de Huidobro sería un adecuado ejemplo de ello porque presenta a un personaje que cae al abismo y que acepta la muerte como fatum. 
romanticismo dialoga con la tradición para superarla/emularla, la vanguardia da un paso más al querer deshacerse no solo del pasado sino también del presente, de ahí que la vanguardia está muriendo desde su nacimiento, como afirma Calinescu (1991: 127). La ruptura vanguardista consiste así en eludir el pasado como si jamás hubiera existido, anhelando el futuro en el instante presente. Ello se traduce en el modo en que la vanguardia legitima su arte, no respecto al pasado, sino a su propio presente: "Un grupo de vanguardia es el que decide un presente, pues el presente del arte no ha sido decidido por el pasado, como suponen los clásicos [...]. El artista no es ni un heredero ni un imitador, sino quien declara con violencia el presente del arte" (Badiou, 2005: 172). Dicho de otra manera, el presente es el tiempo utópico de la vanguardia.

¿Cómo se pone en práctica esa actitud agónica en la obra de arte? Llevando a cabo lo que Peter Bürger denominó “obra inorgánica”, esto es, aquella que rompe con la noción de autor como genio romántico individual y que pone de manifiesto su artificio interno, siendo su proceso de creación/destrucción parte de la propia obra. El ejemplo más evidente para ejemplificarlo son las instrucciones para escribir un poema dadaísta de Tristan Tzara: el poema puede ser escrito por cualquier individuo y/o ser de autoría colectiva, a la vez que su proceso de escritura forma parte de la obra artística. Pero más importante es el detalle de que el texto de Tzara es una receta, es decir, un objeto de la vida cotidiana. Esto último lleva a asimilar las praxis artística y vital, haciendo descender al arte del pedestal donde el romanticismo lo había colocado; el arte vanguardista deviene así objeto desechable cuyo estatus artístico niegan los propios dadaístas.

De esta manera, la respuesta dadaísta a la utopía del presente y a la sacralización del arte fue convertir su obra en un objeto cotidiano hasta el punto de hacerlo desaparecer como producto artístico. Pero otros movimientos de vanguardia buscaron otras vías 
de emanciparse del ideal romántico mediante el abstraccionismo como modo de legitimar su autonomía. Como explica Del Gizzo con respecto al Cuadrado negro sobre fondo blanco de Malévich, el arte puramente abstracto reemplazaba la representación por un repliegue sobre sí mismo y un silencio que inquietara al burgués $\mathrm{y}$, sobre todo, que reivindicara su inutilidad, declarándose como resistencia a Dios, a la patria y a su tradición (2015: 54). Así, los dos cauces escogidos por la vanguardia para secularizarse -de la religión, de la mitología romántica y de la mentalidad burguesasignificaron un despertar de la consciencia acerca de la naturaleza del objeto artístico. Al proyectar el artificio de la obra (inorgánica) o al desacreditar la representación del arte, la vanguardia la despoja de su carácter artístico y, de este modo, se aniquila a sí misma. La vanguardia es, pues, el momento en que el arte moderno se enfrenta directamente consigo mismo $y$, al intentar conciliar arte y vida, decide que todo puede ser artístico o, lo que es lo mismo, que nada es arte porque el arte no se opone a nada. En definitiva, la negación del arte por parte de la vanguardia surge de su propio cuestionamiento; al mirarse a sí mismo, el arte actúa como un Narciso que sí reconoce al reflejo como reflejo, pero, antes que renunciar a él, busca hacer arte de su destrucción.

Entonces, la gran pregunta de la crítica de vanguardia es, ¿qué ocurre después de proclamar la negación del arte? ¿Por qué insistir en su continuación? Tras el declive de las vanguardias históricas, las tres opciones que le quedaban a los artistas eran: 1) admitir que el arte no es un objeto cotidiano y recuperar la sublimidad romántico-idealista pérdida; 2) continuar el ímpetu de ruptura vanguardista como si la novedad pudiera repetirse ad infinitum, o 3) asumir el fin de algunas modalidades artísticas y continuar la senda de otros cauces creativos. Es evidente que, a excepción de ciertos críticos del arte, la última opción no fue la dominante. Durante los años inmediatamente posteriores a las primeras vanguar- 
dias se opera la primera opción: un retorno al orden que devuelve al arte la sublimidad perdida -en el terreno literario, Octavio Paz la denomina "vanguardia otra"-. Pero también persiste la vía de la vanguardia en su corriente más tardía, es decir, el surrealismo, que se podría definir como un nuevo romanticismo, por ejemplo, en su concepto de creación inconsciente o en su exaltación de la libertad individual o social. El surrealista se deja arrastrar por un automatismo, un estado próximo a la inspiración romántica que, como es sabido, había sido problematizada por la propia vanguardia - por ejemplo, mediante la firma colectiva de obras como los manifiestos-. Aunque revolucionario, el surrealismo es una vanguardia moderada porque carece de ese impulso bélico de destrucción de las formas que daba como resultado el abstraccionismo puro, pero comparte con el resto de los movimientos ese debate continuo con lo real.

Décadas más tarde, la vanguardia vuelve a surgir con intensidad durante los años sesenta, en un efecto de "acción diferida" (Foster, 2001), siguiendo el segundo camino, es decir, apelando a la ruptura total como un gesto de continua novedad. Y esta probablemente sea la prueba más evidente de sus contradicciones porque la novedad no es, por definición, un concepto que se pueda repetir al infinito:

Anhelo nunca consumado, lo nuevo sostiene la utopía del arte y lo mantiene alejado de su fin temporal porque "solo por medio de la absoluta negatividad puede el arte expresar lo inexpresable; la utopía”. [...] utopía estética [es]: considerar que la ruptura completa con la tradición no es sino un espejismo [...]. En caso de definirla por su capacidad de novedad, la irrupción vanguardista solo podría ocurrir una vez (Del Gizzo, 2017: 13-15). 
El discurso de la novedad persistente derivó, con el kitsch de los sesenta, a la alineación del arte con el mercado, un destino irónico por parte de un movimiento que nace de su tajante oposición. La alineación con el mercado fue resultado de la exaltación del arte de masas y lo popular, en consonancia con la democracia cultural tan enarbolada por la vanguardia. "Democracia cultural" significa que lo periférico ingresa al centro, que en literatura, por ejemplo, ya no se relatan historias de grandes figuras heroicas, sino que la vida cotidiana de un ciudadano ordinario puede tener interés artístico -de ahí la modernidad del Quijote-. La democracia cultural permitió, asimismo, la coincidencia entre artista-pueblo-público, una equivalencia que le otorga protagonismo a la masa en el terreno artístico. Pero la vanguardia no se percata de que esa equivalencia es un razonamiento heredado del romanticismo, al ser expresión del espíritu del pueblo; consistía más bien en un falso culto de lo popular pues cuando los intelectuales románticos actualizaban mitos y leyendas de su región, existía una autoridad que les otorgaba legitimidad. La relación del romántico con el vulgo es, por tanto, asimétrica y jerárquica. Por su parte, en cambio, la vanguardia lleva al extremo la vinculación entre arte y masas al plantear que el arte puede y debe ser de autoría colectiva. ${ }^{8}$

Y es aquí donde la función del mercado juega un papel crucial pues la vanguardia cree que puede rivalizar con él al crear objetos que, en teoría, se resisten a su mercantilización -por ejemplo, a

${ }^{8}$ Como explica Lukács, la supuesta democracia cultural que defiende la vanguardia entra en tensión con el hermetismo de su arte. En su experimentación formal, el arte de vanguardia se torna incomprensible porque descree de las convenciones y exige un público que desdeñe lo vulgar o superficial; en términos marxistas, hacen de la oscuridad y lo ininteligible, fetichismo de su arte. La vanguardia deviene así un arte hermético y antidemocrático pero basado en postulados democráticos, contradicción que se traduce en un arte de y para el pueblo, pero sin el pueblo (1966b: 316). 
través del abstraccionismo-. ${ }^{9}$ La contradicción en que cae la vanguardia es la ilusión de crear objetos de arte que no sean absorbidos por el mercado. En términos marxistas, la vanguardia busca devolver al arte el valor de uso que el mercado reemplaza por el valor de cambio, neutralizando el objeto artístico como un objeto ordinario más. Por ello, la vanguardia cae en una paradoja inconsciente al querer sustituir una falsa equivalencia -el valor de cambio- por otra falsa equivalencia -objeto de arte como sinónimo de objeto de uso cotidiano-. Lo que la vanguardia no pudo asumir es que el único medio para combatir el mercado no era el arte sino la lucha política contra la vida burguesa y liberal. ${ }^{10}$ Pero la historia demostró que esa revolución fue fallida: o bien el arte derivó en el kitsch de los ańos sesenta y se mercantilizó, o bien el tratamiento de lo popular se tornó de élite. Ambas vías llevaron a Adorno a reconocer que la alta cultura es la única que puede resistirse al mercado (2014: 46).

Por su parte, Jean Clair declara al respecto: "la secularización del arte que suponía la modernidad, no anunciaba su autonomización, firmaba su sometimiento a las fuerzas de un Mal aún peor" (1998: 58), es decir, el mercado. Porque al arte no le queda más remedio que asumir su mercantilización o poner en práctica aquello que quiso destruir, esto es, sublimar el objeto artístico y devolverlo al pedestal romántico de donde lo arrebató para entregárselo al mercado. En este sentido, la vanguardia es un intento

${ }^{9}$ Compagnon ofrece el ejemplo de un cuadro de Kooning expuesto por Raushenberg quien, al borrar la firma y colocar la suya propia, demuestra que la firma del artista deviene la nueva marca del objeto artístico (1991: 88-95).

${ }^{10}$ Sanguineti explica que es el mercado el que decreta la separación entre cultura y política, pues el único modo de combatirlo es mediante el divorcio entre cultura y política, ya que vanguardia y compromiso son conceptos incompatibles (1972a: 29). El arte comprometido, sigue Sanguineti, sacrifica su autonomía, se convierte en política y pierde así su carácter estético (1972a: 29-30). 
arrepentido de secularización del arte. Porque su operación consistió, más bien, en un proceso de desplazamiento que no reemplaza las formas sustanciales de la sacralización romántica, sino que se metamorfosea en un disfraz moderno que no es tal, sino que es, más bien, "antimoderno", según la definición de "antimodernidad" ya expuesta. Si el romanticismo habría desplazado la religión hacia la idealización del arte, la vanguardia trata de desbaratar esa sublimidad artística, pero su intención deriva en continuar dicho desplazamiento.

\section{La novela, el género secularizado}

Pero cabría preguntarse si todas las manifestaciones artísticas caen en la misma contradicción o si existe alguna diferencia relevante entre las mismas que relativice la hipótesis mencionada. Nuestra propuesta se inclina por la segunda opción, lo que ejemplificaremos y justificaremos ateniéndonos al terreno literario, a partir de la oposición entre poesía y prosa; en concreto, entre poesía y novela, para sugerir que, si la poesía efectivamente ha caído presa de las contradicciones de la vanguardia, la novela se irguió victoriosa de sus novedades.

La poesía fue el género que mejor se adecuó a la obra inorgánica de vanguardia debido a su brevedad, pero, sobre todo, porque su desacralización, en apariencia, fue total. La lírica era el género sublime por excelencia y poseía unas características que, si bien evolucionaron a lo largo de la historia, no se cuestionaron hasta el romanticismo. Fueron los románticos los primeros interesados en elucidar la naturaleza de lo poético, afán heredado por la vanguardia. De alguna manera, podríamos decir que a la pregunta becqueriana "qué es poesía", el dadaísmo responde "nada" en su intento de secularización del arte; porque contra esa sublimidad de lo poético acechó la vanguardia con vehemencia. Entonces, a 
priori, la vanguardia habría alcanzado su objetivo, por ejemplo, al hacer de la poesía una mera receta de cocina. Pero si el arte no se diferencia de una fórmula culinaria, entonces, ¿qué es? La poesía se resiste a responder esa cuestión.

Frente a la poesía, la novela es, por su modernidad, el género literario secularizado. Si nos retrotraemos al Quijote, observamos cómo allí se manifiesta ese despertar de la modernidad en el cuestionamiento de la ficción y de los géneros establecidos. Además, como es sabido, en el Quijote se tematiza la realidad contemporánea con un interés que no había tenido hasta entonces. No obstante, definir el género novelístico es uno de los desafíos más controvertidos de la crítica actual debido a su hibridez estilística y experimentación formal; el término puede albergar discursos críticos, científicos, entremezclados con la ficción, dando lugar a obras ambivalentes que presentan, por ejemplo, toda una teoría literaria intercalada en una trama totalmente ficcional.

Sin duda, uno de los estudios críticos más rigurosos acerca de la teoría de la novela es la obra del primer Lukács. El crítico define el género como "proceso en sí mismo", de ahí que ya la novela moderna sería la primera manifestación anacrónica de obra inorgánica, mucho antes de que la vanguardia sacara provecho de esa noción. Añade Lukács la definición, muchas veces citada, de “epopeya de un mundo sin dioses" (1966a: 81); la novela se presenta así como el único género que, por su modernidad, remite a unas coordenadas históricas concretas porque responde al proceso de secularización y la desacralización de los viejos saberes religiosos. La novela no da respuestas, por el contrario, crea preguntas que, en ocasiones, ella misma desconoce, pero son detectadas por lecturas ajenas en diferido, y solo las mejores "devienen aptas para simbolizar lo esencial de lo que está por decirse arte” (Lukács, 1966a: 81). Cuando Lukács afirma que únicamente la novela genera interrogantes, no niega que otros géneros posean esa capacidad, sino que 
es la escisión formal y de contenido su rasgo más característico, de ahí su modernidad. Porque la modernidad es el paradigma de la disonancia y lo contradictorio, y las estrategias retóricas más adecuadas para proyectar esa escisión serían la ironía y la (auto) parodia:

[...] y ese discernimiento que es ironía se vuelve tanto contra sus héroes [...] como contra su propia sabiduría [...]. Capta, no solamente lo que esa lucha tiene de desesperada, sino lo que su cesación tiene de más desesperada, [...] muestra también que la superioridad del mundo se debe mucho menos a su propia fuerza [...] que a una problemática interna [...] del alma cargada de ideal [...]. La ironía del escritor es la mística negativa de las épocas sin Dios: [...] es a ese título que la ironía constituye [...] la objetividad de la novela (Lukács, 1966a: 78-83).

Destacamos el final de la cita debido a la carga paradójica que desprende; no es que Lukács afirme que la ironía sea objetiva, sino que la novela no puede alcanzar la objetividad porque el propio narrador es una categoría escindida por su modernidad, a diferencia del narrador premoderno. La modernidad, entendida en su acepción de renovación, implica la autoconsciencia y reflexión sobre sí mismo, de ahí que la novela se inicie de la mano de la parodia, es decir, surja con un sentido crítico y con una intención de oposición a una tradición que la antecede; por tanto, es el único género que se define por la ruptura de sí mismo; es, dice Lukács, su propia caricatura (1966a: 66-67). Es el único género que tiene la capacidad de emplear sus propias estrategias para desacralizarse a sí misma, gracias a su heterogeneidad, y a su falta de definición y delimitación. De ahí que la vanguardia, en su afán de destrucción, no puede demoler lo que ya se presenta derribado. 
La modernidad de la novela se alcanza, además, al albergar elementos convencionalmente ajenos a lo literario; por ello, es contradictorio considerar que una de las novedades de la novela del siglo xx sea precisamente su heterogeneidad. Esto contradice algunas falacias conceptuales en que ha caído la crítica en ocasiones. En primer lugar, la idea de la "muerte de la novela" basada en que la narrativa posmoderna rompe con una serie de barreras propias del género. Si la novela se define por la ruptura formal y de contenido, entonces no puede morir realizando el mismo gesto por el cual surgió. El género novelístico es desde su origen un señalamiento, un modo de plantear y preguntarse acerca de la naturaleza de la ficción: en qué consiste y de qué modo funciona.

Por ello sería erróneo, comparativamente, considerar la parodia como una modalidad literaria menor, pues el diálogo con otros textos es, siguiendo a Bajtín (2004), un rasgo constitutivo de toda novela. Parodia y ruptura ocupan un lugar central en el género, aunque ello no implica una separación tajante con el pasado sino exactamente lo contrario: la novela moderna privilegia la tradición por encima de todo, se focaliza en ella y de ella depende para configurarse. Parodia e ironía comparten con la modernidad su carácter ambivalente: ambos procedimientos tienen un objetivo contra el cual ensañarse mediante el homenaje y la desacralización simultáneamente. De ahí que, aunque la poesía fuera el género vanguardista por excelencia, lo cierto es que la novela, sin caer en las contradicciones de la poesía, sacó más provecho de un movimiento cuyo objetivo era la desacralización y la destrucción. Incluso la desacreditada novela realista fue un paso radicalmente moderno en la evolución del arte, como explica Jauss;

[...] la novela en prosa, [...] contrariamente al concepto de poesía y de totalidad de Hugo, se apoderó de la actualidad histórica y alcanzó validez universal. [...] el fracaso del drama romántico 
indica lo que no podía cumplirse en la obra de Hugo porque ya había sido superado por el proceso general de la evolución literaria: la esperanza de que el moderno estado del mundo pudiera captarse como totalidad en el medio de la poesía [...]. En definitiva, el fracaso de esta esperanza viene a confirmar el diagnóstico de Hegel y de Heine sobre su propia época: que con el final del período artístico, el arte debía fracasar si creía poder representar el conjunto de la cambiante realidad de forma objetiva, épica e ingenua (1995: 134-135).

La larga cita es necesaria porque resume varios planteamientos que venimos esbozando: la capacidad de la novela para adaptarse al devenir histórico frente al fracaso de la poesía. Porque la novela es, de alguna manera, esa "prosa del pensar" que Hegel intuía como la evolución artística cuando se dejara atrás la "sensibilidad reconciliada del espíritu” y la poesía de la representación (Hegel, 1989: 66). El pronóstico de Hegel se habría cumplido si la vanguardia hubiera asumido la categorización histórica del arte y admitiera, en consecuencia, que algunas fórmulas artísticas caducan y que, en el terreno literario, ella misma fue quien abanderó la destrucción de la poesía.

\section{Conclusiones}

Iniciamos nuestro trabajo adscribiéndonos a la escisión entre dos modernidades para explicar el proceso de secularización. Nuestra propuesta es que la secularización en sentido estricto nunca se llevó a cabo debido a que la vía de la modernidad que se tornó hegemónica no fue más que una antimodernidad oculta. Tal modernidad explica la evolución artística desde el Barroco hasta la vanguardia y esta última fue, desde nuestro punto de vista, un intento fallido de secularizar el arte del ideal y la sublimidad romántica. De ahí que 
hemos intentado situar la vanguardia en el proceso de la antimodernidad aunque hemos matizado que no todas las manifestaciones artísticas se incluyen en el mismo; nuestra sugerencia es que, en el terreno literario, la novela fue el único género secularizado debido a su origen moderno y la naturaleza desacralizadora de sí mismo, frente a la sublimidad de la poesía. Quizá sea necesario y enriquecedor ampliar dichas conclusiones a otras ramas del arte para comprobar si esa secularización desplazada de la vanguardia se aplica de la misma manera en todos los casos.

\section{Bibliografía}

Adorno, Theodor, 2014, Teoría estética, Jorge Navarro Pérez (trad.), Akal, Madrid.

Álvarez Yágüez, Jorge, 2021, "La crítica de la modernidad en el pensamiento decolonial", Res Pública. Revista de Historia de las Ideas Politicas, vol. I, núm. 24, pp. 1-15.

Badiou, Alain, 2005, El siglo, Hugo Acevedo (trad.), Manantial, Buenos Aires.

Bajtín, Mijail, 2004, Problemas de la poética de Dostoievski, Tatiana Bubnova (trad.), Fondo De Cultura Económica, Madrid.

Berman, Marshall, 2011, Todo lo sólido se desvanece en el aire, Andrea Morales (trad.), Siglo xxi, Madrid.

Bürger, Peter, 1987, Teoría de la vanguardia, Jorge García (trad.), Barcelona, Península.

Calinescu, Matei, 1991, Cinco caras de la modernidad. Modernismo, vanguardia, decadencia, kitsch, posmodernismo, María Teresa Beguiristain (trad.), Tecnos, Madrid. 
Clair, Jean, 1998, La responsabilidad del artista. Las vanguardias, entre el terror y la razón, José Luis Arántegui (trad.), Visor, Madrid.

Compagnon, Antoine, 1991, Las cinco paradojas de la modernidad, Julieta Fombona

Zuloaga (trad.), Monte Ávila Ediciones, Caracas.

, 2007, Los antimodernos, Manuel Arranz (trad.), Acantilado, Barcelona.

Davis González, Ana, 2021, Vanguardia y refundación nacional en Adán Buenosayres, Peter Lang, Berlín.

De Micheli, Mario, 2015, Las vanguardias artísticas del siglo XX, Ángel Sánchez Gijón (trad.), Alianza, Madrid.

Del Gizzo, Luciana, 2015, “Autonomía vs. legitimidad, un dilema vanguardista. El caso del invencionismo", Letral, núm. 14, pp. 53-67.

,2017, Volver a la vanguardia. El invencionismo y su deriva en el movimiento poesía buenos aires (1944-1963), Aluvión, Madrid.

Eagleton, Terry, 1997, Las ilusiones del posmodernismo, Marcos Mayer (trad.), Paidós, Buenos Aires.

Foster, Hal, 2001, El retorno de lo real. La vanguardia a finales de siglo, Alfredo Brotons Muñoz (trad.), Akal, Madrid.

Habermas, Jürgen, 1993, El discurso filosófico de la modernidad, Manuel Jiménez Redondo (trad.), Taurus, Madrid.

Hauser, Arnold, 1992, Historial social de la literatura y del arte 3, A. Tovar y F. P. Varas-Reyes (trads.), Labor, Barcelona.

Hegel, G. W. H., 1989, Lecciones de estética, Raúl Gabás (trad.), Edicions 62, Barcelona.

Jauss, Hans-Robert, 1995, Las transformaciones de lo moderno. Estudios sobre las etapas de la modernidad estética, Visor, Madrid. 
, 2000, La historia de la literatura como provocación, Juan Godo Costa y José Luis Gil Aristu (trads.), Península, Barcelona.

Lukács, Georg, 1966a, Teoría de la novela, Juan José Sebreli (trad.), Siglo Veinte, Buenos Aires.

, 1966b, Problemas del realismo, Carlos Gerhard (trad.), Fondo de Cultura Económica, México.

Poggioli, Renato, 2011, Teoría del arte de vanguardia, Rosa Chacel (trad.), Universidad Nacional Autónoma de México, México.

Rancière, Jacques, 2011, El destino de las imágenes, Pablo Amador (trad.), Politopías, Pontevedra.

Sanguineti, Edoardo, 1972a, "Vanguardia, sociedad, compromiso", en Por una vanguardia revolucionaria, Irene Cusien (trad.), Tiempo contemporáneo, Buenos Aires, pp. 11-36.

, 1972b, "Sociología de la vanguardia", en Por una vanguardia revolucionaria, Emilio Renzi (trad.), Tiempo contemporáneo, Buenos Aires, pp. 81-119.

Sebreli, Juan José, 2000, Las aventuras de la vanguardia. El arte moderno contra la modernidad, Sudamericana, Buenos Aires. 